\title{
WORKSHOP ON ATMOSPHERIC FORCING OF OCEAN CIRCULATION
}

$\mathrm{T}$ he Workshop was conducted at Tulane University in New Orleans on January 5-7, 1988. Approximately 100 invited scientists from Great Britain. France, Germany, Canada, and the United States participated. The concept of the Workshop originated with the Institute for Naval Oceanography (INO), NSTL, MS. The Organizing Committee consisted of: Dr. James Scoggins, Texas A\&M University (Chairman), Dr. Kenneth Davidson, Naval Postgraduate School, Dr. Robert Weller, Woods Hole Oceanographic Institution, Dr. Christopher N.K. Mooers, INO, Dr. Jagadish Shukla, University of Maryland, Dr. William Large, National Center for Atmospheric Research (NCAR), Dr. Frank O. Bryan, (NCAR), Dr. Jordan Alpert, National Meteorological Center, Mr. David Legler, Florida State University, and Mr. Robert Willems, INO. Committee members were chosen who could represent the WOCE and U.S. TOGA programs; both later became co-sponsors of the Workshop with INO.

It was recognized that before the atmosphere and the ocean could be understood as an interacting, coupled system, each part must be understood with emphasis on the air-sea interface. Specifically, the Workshop addressed how to measure and integrate fluxes of heat, moisture, and momentum at the air-sea interface into models, and how to improve the models and their interactions.

Objectives of the Workshop were: 1) Review present status of the prescription of atmospheric forcing of the ocean and needs for improvement for routine (operational) data, research data sets, and numerical models; 2) Define the scientific issues, including the status of algorithms and parameterizations; role of boundary layer models, unconventional data, and coupled atmosphereoceanic models; and, clarify limiting factors; and 3) Recommend an overall plan of research on atmospheric forcing of ocean circulation, taking into account the requirements of INO, WOCE, and TOGA.

The objectives were addressed by defining seven scientific issues, each of which was considered by a working group composed of about 15 scientists. The issues were: 1) Bulk Parameterization Schemes for Air-Sea Flux Computations; 2) Computation of Global AirSea Flux Climatology; 3) Atmospheric Forecast Model Data Assimilation and Air-Sea Flux Computations; 4) Ocean Model Sensitivity to Atmospheric Forcing; 5) Ocean Surface Boundary Conditions; 6) In Situ Networks; and 7) Satellite Missions.

The Workshop consisted of overview or position presentations, poster papers, and extensive working group sessions. The interaction of working groups was encouraged and topics were coordinated through plenary sessions held following each series of working group sessions. Charges to the working groups provided guidelines for discussion.

Each working group was asked to review the status of its topic, define significant problems, and recommend a plan of research. A Workshop report detailing the position presentations, poster papers, and working group reports will be published by the by the INO by midsummer. Copies of the report may be obtained by contacting Mr. Robert $\mathrm{C}$. Willems, (601) 688-5737, INO, NSTL, MS, 39529.

The Institute for Naval Oceanography is sponsored by the Navy and administered by the Office of the Chief of Naval Research.

Contributed by James R. Scoggins, Chairman, Organizing Committee, and Professor and Head, Department of Meteorology, Texas A\&M University.

\section{OCEAN OPTICS IX CONFERENCE}

The held as held as part of the Society of PhotoOptical Instrumentation Engineers (SPIE) Southeast Symposium from 4-6 April, 1988 in Orlando, Florida.

This meeting is generally held biennially and attendance has grown at a steady rate for each of the last four meetings. Approximately 150 scientists, engineers and program managers attended this year's conference. The conference was chaired by Marvin Blizard of the Office of Naval Research (ONR) and co-chairs conducted the following sessions: Concepts and Theory (George Kattawar, Texas A\&M University), Ocean Optical Properties (Ros Austin, Scripps Institute of Oceanography), Instrumentation (Marvin Blizard),
Laser Bathymetry (G. Dan Hickman, NORDA), Particle Optics (Rick Spinrad, ONR), Imaging (Jules Jaffe, Woods Hole Oceanographic Institute), and Remote Sensing and Animal Vision (Henri Hodara, Tetra Tech, Inc.). Some 55 papers were delivered during the conference.

These talks will be published in about three months and copies of the proceedings (the specific volume will be number 925, entitled "Ocean Optics IX") will be available for purchase from the offices of SPIE (P.O. Box 10, Bellingham, WA 98227-0010, telephone 206676-3290).

Contributed by Richard W. Spinrad. Program Manager for Ocean Optics, Office of Naval Research. 